\title{
Outbreak of Rickets in Pigs in the West of Santa Catarina
}

\author{
Anderson Gris', Eduardo Peres Neto ${ }^{2,3}$, Kalinka Schimitti da Silva ${ }^{2,3}$, Teane Milagres Augusto Gomes ${ }^{2}$, \\ Soraya Regina Sacco Surian ${ }^{2}$, Nei Fronza ${ }^{4}$ \& Ricardo Evandro Mendes ${ }^{2}$
}

\begin{abstract}
Background: Rickets is a deficiency pathology that occurs in young and growing animals, leading to deficient bone mineralization. Rickets has been reported in several species producing numerous economic losses. The disease is caused by nutritional imbalance of calcium $(\mathrm{Ca})$, phosphorus $(\mathrm{P})$ and vitamin $\mathrm{D}$. The aim of this work was to report two outbreaks of rickets in commercial weaning farms in the Seara city, in the western region of Santa Catarina State (SC), Brazil.

Case: In August 2016, the Veterinary Pathology Laboratory (LPV) at the Concórdia Campus of the Catarinense Federal Institute (IFC) diagnosed two outbreaks of rickets in pigs in the weaning phase in Seara, SC. The clinical history was obtained by interviewing the field veterinarian and the farmers. In the anamnesis, both pig farmers stated having used a feed premix product from the same company, starting three months ago, and after that the pigs presented clinical signs of posterior paralysis and progressive weight loss. Six animals were submitted to necropsy and organs were collected from the abdominal and thoracic cavities; central nervous system and bones; fixed in 10\% buffered formalin, routinely processed, paraffin embedded and stained with hematoxylin and eosin (HE) for histopathological analysis. Bone specimens were decalcified in nitric acid working solution 20 times their volume, during 5 days. In addition, samples of the premix product containing minerals and vitamins were sent to a specialized laboratory to analyze macroelements levels through the atomic absorption methodology. In property 1, there was a batch of 100 animals, the morbidity rate was $15 \%$ and lethality was $5 \%$. In property 2, among 30 animals, the morbidity and lethality rate were $33 \%$. Five animals from property 1 and one animal from property 2 underwent necropsy, that showed severe bone fragility and flexibility (6/6), growth plate discontinuity (2/6), as well as, increased volume of costochondral joints (rachitic rosary) and epiphyseal cartilage thickening (2/6). Regarding the premix used in both farms, the label showed manufactured guarantee of $110 \mathrm{~g} / \mathrm{kg}$ of Ca (minimum), $62 \mathrm{~g} / \mathrm{kg}$ of total P and 38,400 I.U./kg of vitamin D. Meanwhile the analysis of the product used in the feed mixture quantified $74.3 \mathrm{~g} / \mathrm{kg}$ of $\mathrm{Ca}$ (minimum), $22.2 \mathrm{~g} / \mathrm{kg}$ of total P and 40,098.9 I.U./kg of vitamin D. The diagnosis of rickets was established through the association of history, clinical signs, macroscopic, microscopic lesions and nutritional analyses.

Discussion: The affected pigs weighed approximately $20 \mathrm{~kg}$ and consumed an average of $1.0 \mathrm{~kg}$ of feed per day. The recommended amount of feed consumption for pigs at this stage is approximately $953 \mathrm{~g}$ in American literature, while national recommendations described a consumption of 1,036 g/animal. Comparing information in the product label and laboratory analyses, the real level of Calcium was $32.4 \%(35.6 \mathrm{~g} / \mathrm{kg})$ lower in the product, as well as total Phosphorus level, 64.2\% (39.8 g/kg) lower. On the other hand, Vitamin D levels were 4.4\% (1,698.9 I.U.) above guarantee provided by the company. It is concluded that rickets in pigs raised intensively occurred due to non-observance of the minimum intake levels of Ca, P and Vitamin D in the diet. Although this is an evident conclusion, taking into account the industry's technification in Brazil, error in the formulation of the diet leading to animal mortality and serious economic losses to farmers should not be expected.
\end{abstract}

Keywords: hypocalcemia, metabolic bone disease, rickets, swine, vitamin D. 


\section{INTRODUCTION}

Brazilian pig breeders are highlight in production, technology and quality in order to meet the demanding world market. Brazil is the fourth largest producer of swine in the world, and Santa Catarina state (SC) is the main national producer, with $28 \%$ of slaughtered animals and responsible for $40 \%$ of exports [1]. Despite all efforts, some pathological and metabolic diseases that should have been controlled remain in the herds, with small, but constant occurrence.

The three main metabolic bone diseases are rickets, osteomalacia and osteoporosis. Rickets occur in young and growing animals, leading to poor bone mineralization. The disease has been reported in several species [7].

In the last two decades, rickets in pigs received little attention because nutritional programs provided calcium $(\mathrm{Ca})$, phosphorus $(\mathrm{P})$, and vitamin D supplementation sufficient for normal bone growth and mineral homeostasis. Currently, commercial diets for pigs are specifically adapted for the production of lean muscle mass and growth, with less consideration for bone formation [14]. Bone growth is mainly related to the metabolism of calcium $(\mathrm{Ca})$, phosphorus $(\mathrm{P})$, magnesium $(\mathrm{Mg})$, parathyroid hormone $(\mathrm{PTH})$, vitamin $\mathrm{D}$ and bone alkaline phosphatase [4].

Pigs are sensitive to the development of rickets due to high growth rate and limited exposure to sunlight. Moreover, the high weight gain favors the development of lesions in the locomotor system, due to biomechanical stress, leading to higher production costs [2].

The aim of the present study was to report two outbreaks of rickets in commercial weaning farms in the Seara city, western region of the state of Santa Catarina, Brazil.

\section{CASE}

In August 2016, the Veterinary Pathology Laboratory (LPV) at the Concórdia Campus of the Catarinense Federal Institute (IFC) diagnosed two outbreaks of rickets in pigs in the weaning phase in two farms, in the Seara city, state of Santa Catarina.

The clinical history was obtained by interviewing the field veterinarian and the farmers. Six animals were submitted to necropsy and organs were collected from the abdominal and thoracic cavities; central nervous system and bones; fixed in $10 \%$ buffered formalin ${ }^{1}$, routinely processed, paraffin embe- $\mathrm{dded}^{2}$ and stained with hematoxylin and eosin $(\mathrm{HE})^{2}$ for histopathological analysis. For the histopathology of bone, they were decalcified in nitric acid ${ }^{3}$ working solution 20 times their volume, during 5 days, and routinely processed as described before.

In addition, samples of the premix product containing minerals and vitamins were sent to a specialized laboratory to conduct analyses of the macroelements and vitamin D levels through the atomic absorption methodology [18]. The levels of $\mathrm{Ca}$ and $\mathrm{P}$ in the other compounds of the diet (ground maize and soybean meal) were calculated based on the levels of nutrients in the feed formula and the data from the Brazilian table for poultry and swine [17].

In the anamnesis, both pig farmers stated having used a feed premix product from the same company, starting three months ago, and after that the pigs presented clinical signs of posterior paralysis (Figure 1) and progressive weight loss. In property 1 , with a batch of 100 animals, the morbidity rate was $15 \%$ and lethality was $5 \%$. Property 2 , with a batch of 30 animals, presented a morbidity and lethality rate of $33 \%$.

Five animals from property 1 and one animal from property 2 underwent necropsy, showing severe bone fragility and flexibility (6/6), growth plate discontinuity (2/6), and increased volume of costochondral joints (rachitic rosary) with epiphyseal cartilage thickening (2/6) [Figure 2].

Histopathological examination revealed thin bone spicules with a moderate number of islands of hypertrophic chondrocytes. In the growth plate of the femoral epiphysis, the chondrocyte columns were disorganized in all animals with bone spicules filled with pale pink, unmineralized osteoid (Figure 3).

According to the farmers and the premix label, $68 \mathrm{~kg}$ of ground corn, $27 \mathrm{~kg}$ of soybean meal and $5 \mathrm{~kg}$ of the premix were used for each $100 \mathrm{~kg}$ of total feed. In the anamnesis, the producers reported that the affected pigs weighed approximately $20 \mathrm{~kg}$ and consumed an average of $1.0 \mathrm{~kg}$ of feed per day. The recommended amount of feed consumption for pigs at this stage is approximately $953 \mathrm{~g}$ [17], while the recommendation of the National Research Council (NRC) [15] is a consumption of $1,036 \mathrm{~g}$ per animal.

The total amounts of minerals provided by ground corn and soybean meal [17] were calculated for $100 \mathrm{~kg}$ of feed, and they corresponded to 13.6 $\mathrm{g}$ and $64.8 \mathrm{~g}$ of $\mathrm{Ca} ; 197.2 \mathrm{~g}$ and $159.3 \mathrm{~g}$ of $\mathrm{P}$ (total) 
respectively. In the same amount of feed, the levels of minerals provided by the premix, second to the laboratory results were $371.6 \mathrm{~g}$ of $\mathrm{Ca}, 111.0 \mathrm{~g}$ of $\mathrm{P}$ (Total) and 200,494.5 I.U. of Vitamin D.

In Table 1 , the amount of $\mathrm{Ca}$, total $\mathrm{P}$ and vitamin $\mathrm{D}$ consumed by the pigs according to the laboratory analysis and the product label were shown. These data were compared with the total requirement of these minerals and vitamins with NRC [15] and the Brazilian table for poultry and swine [17].

In relation to the premix used in both farms, the company established guarantee levels of $110 \mathrm{~g} / \mathrm{kg}$ of $\mathrm{Ca}$ (minimum), $62 \mathrm{~g} / \mathrm{kg}$ of total P and 38,400 I.U./ $\mathrm{kg}$ of vitamin D. However, the analysis of the product used in the mixture of the diet quantified $74.3 \mathrm{~g} / \mathrm{kg}$ of $\mathrm{Ca}$ (minimum), $22.2 \mathrm{~g} / \mathrm{kg}$ of total P and 40,098.9 I.U./ $\mathrm{kg}$ of vitamin D. This represents $32.4 \%(35.6 \mathrm{~g} / \mathrm{kg})$ less of $\mathrm{Ca}$ and $64.2 \%(39.8 \mathrm{~g} / \mathrm{kg})$ less of total P, but Vitamin D levels were $4.4 \%$ (1,698.9 I.U.) above the guarantee level provided by the company.

\section{DISCUSSION}

The diagnosis of rickets was established through the association of history, clinical signs, macroscopic and microscopic lesions and nutritional analyses. In the literature [14], the morbidity rates range between 2 and $40 \%$ of the batch and a mortality between 10 and $20 \%$, similar to the reported outbreak.

Vitamin D deficiency in animals leads to retarded growth, lameness, posterior train paralysis, clinical signs of calcium and magnesium deficiency, rachitic rosary, enlarged joints, and apathy; the body weight of the pigs may favor the arching of the legs [2]. The progressive weight loss observed can be explained due to the difficulty in locomotion, which in this case was reported as loss of posterior. The posterior paralysis or dog-sitting posture is observed in pigs with rickets, however, it is nonspecific [7]. But this is also observed in other animals, such as birds, when they present pain, movement difficulty, and consequently progressive weight loss [11].

The classic rickets lesions in all species described in the literature are characterized by increased joint volume, being marked in the costochondral region, thickening of epiphyseal cartilage, decreased bone density and spontaneous fractures [7]. These lesions are compatible with those found in the outbreaks in this study, although spontaneous fractures were not found in these cases, probably due to the low weight of the animals, which were young and small. Microscopically, there was persistence of hypertrophic cartilage zones and thickening of demineralized bone spicules [14]. The pathological findings found in this report were similar to those reported in sheep and broiler chickens $[8,9]$.

According to Table 1, when the data of the laboratory analysis are compared to NRC [15] there are deficiencies of $2.7 \mathrm{~g}(38.5 \%)$ of Calcium and $1.6 \mathrm{~g}$ (26.6\%) of total Phosphorus. On the other hand, Vitamin D supplementation was 1,710.7 I.U. (855.3\%) above the minimum recommendation. It was also observed that calcium deficiency remained even when the premix had the amounts expressed on the label (-1.0 g [-14.3\%]).

The data of Table 1, when compared to the Brazilian table for poultry and swine [17], regardless of the laboratory report or the label information, hypocalcemia, hyperphosphatemia and hypovitaminosis D were observed. Hypocalcemia can be associated with sudden death in vitamin D-deficient diets, although is an unexpected clinical presentation [14]. This observation suggests that vitamin D-dependent rickets in pigs has the potential to be associated with lethal hypocalcemia.

For growing pigs, the assumed maximum level of vitamin D3 for long-term feeding conditions (over 60 days) is 2,200 I.U. D3/kg of food intake. The supplemented vitamin D levels may lead to toxicity, but there is only enough information available to define a minimum tolerance for vitamin D3 supplementation [10]. A very high level of vitamin D can mobilize excessive amounts of calcium and phosphorus from bones [15], contributing to the development of rickets.

Adequate amounts of vitamin $\mathrm{D}$ are also required for $\mathrm{Ca}$ and $\mathrm{P}$ metabolism, and vitamin $\mathrm{D}$ deficiency reduces the retention of $\mathrm{Ca}, \mathrm{P}$ and $\mathrm{Mg}$ [15]. Vitamin $\mathrm{D}$ deficiency causes disturbances in the absorption and metabolism of $\mathrm{Ca}$ and $\mathrm{P}$ that result in insufficient bone calcification. In severe vitamin D deficiency, pigs may exhibit signs of $\mathrm{Ca}$ and $\mathrm{Mg}$ deficiency, including tetany $[12,15,16]$.

Adequate levels of $\mathrm{Ca}$ and $\mathrm{P}$ in the diet for all classes of pigs is dependent on: (1) an adequate supply of each element in an available form in the diet, (2) an adequate ratio of $\mathrm{Ca}$ and $\mathrm{P}$ available in the diet; and (3) the presence of adequate amounts of vitamin D [15]. A wide ratio of $\mathrm{Ca}$ and $\mathrm{P}$ reduces $\mathrm{P}$ absorption, leading to reduced growth and bone calcification, especially if the diet is marginal in $\mathrm{P}$. 
Table 1. Consumption of Ca, total P and vitamin D (Vit. D) of the pigs with $20 \mathrm{~kg}$ and consumption of $0.953 \mathrm{~kg}$ of feed, according to laboratory analysis and label information, and comparing with the National Research Council (NRC)* and Brazilian table** for poultry and swine.

\begin{tabular}{ccccccccc}
\hline & $\begin{array}{c}\text { Lab. } \\
\text { results (1) }\end{array}$ & $\begin{array}{c}\text { Label } \\
(2)\end{array}$ & $\begin{array}{c}\text { Requirement } \\
(3)^{*}\end{array}$ & $\begin{array}{c}\text { Requirement } \\
(4)^{* *}\end{array}$ & $\begin{array}{c}\text { Difference } \\
1-3\end{array}$ & $\begin{array}{c}\text { Difference } \\
2-3\end{array}$ & $\begin{array}{c}\text { Difference } \\
1-4\end{array}$ & $\begin{array}{c}\text { Difference } \\
2-4\end{array}$ \\
\hline Ca (g) & 4.3 & 6.0 & 7.0 & 7.9 & -2.7 & -1.0 & -3.6 & -1.9 \\
P total (g) & 4.4 & 6.5 & 6.0 & 3.9 & -1.6 & +0.5 & +0.5 & +2.6 \\
Vit. D (I.U.) & $1,910.7$ & $1,829.7$ & 200 & $2,953.5$ & $+1,710.7$ & $+1,629.7$ & $-1,042.8$ & $-1,123.8$ \\
\hline
\end{tabular}

*National Research Council (NRC) [15]; ${ }^{* *}$ Brazilian table for poultry and swine [17].

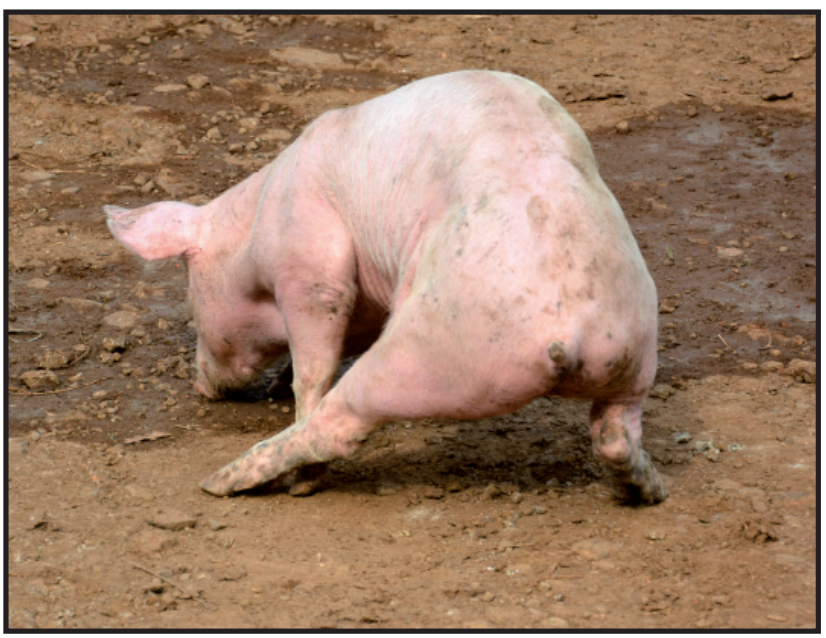

Figure 1. Swine with rickets showing signs of ataxia due to posterior paralysis.

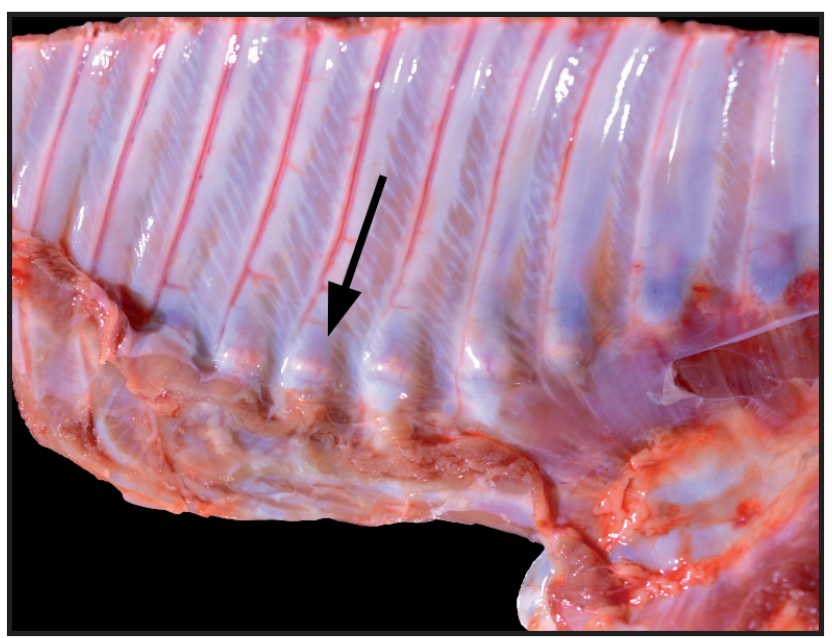

Figure 2. Parietal pleural surface, increased volume of costochondral joints (arrow): Rachitic rosary.

A suggested ratio of $\mathrm{Ca}$ to total $\mathrm{P}$ for soybean meal diets is between $1: 1$ and 1.25:1. A closer $\mathrm{Ca}$ and $P$ ratio will probably result in efficient use of $P$ being one of the most expensive ingredients in the diet. An adequate amount of vitamin $\mathrm{D}$ is also required for proper metabolism of $\mathrm{Ca}$ and $\mathrm{P}$, but a very high level of vitamin $\mathrm{D}$ can mobilize excessive amounts of $\mathrm{Ca}$ and $\mathrm{P}$ from bones [15].

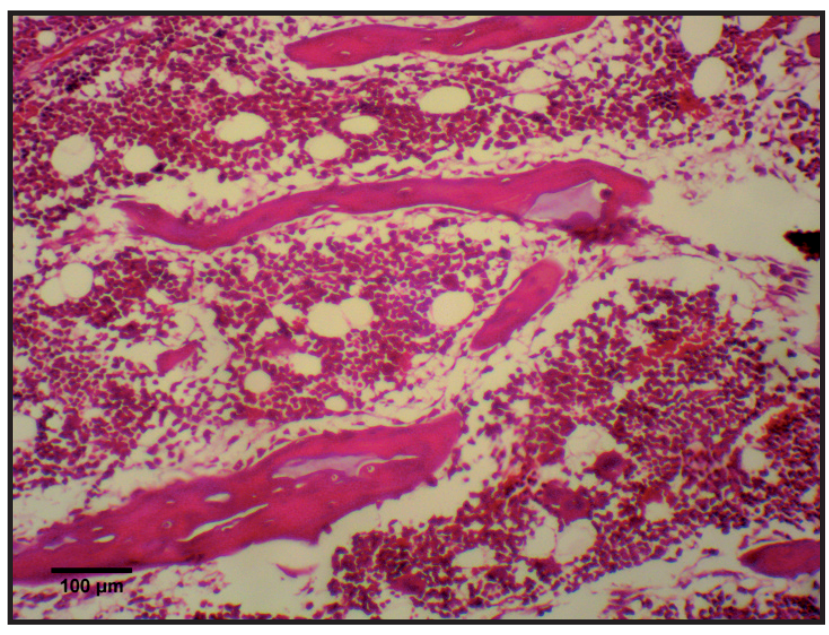

Figure 3. Microscopic view of trabecular bone from swine with rickets. Haversian systems are filled with pale pink, unmineralized osteoid [HE; 100x].

Signs of Ca or P deficiency are similar to those of vitamin D deficiency, and include reduced growth and poor bone mineralization, resulting in rickets in young pigs and osteomalacia in adults. Excessive levels of $\mathrm{Ca}$ and $\mathrm{P}$ may reduce performance of pigs [15], and the effect is greater when the $\mathrm{Ca}: \mathrm{P}$ ratio is increased. Excessive $\mathrm{Ca}$, not only decreases the use of $\mathrm{P}$, but also increases the need for zinc in the presence of phytate [15]. According to the premix analysis, the relation between $\mathrm{Ca}$ and $\mathrm{P}$ in the diet provided was 3.3:1.

The increased ratio of digestible $\mathrm{Ca}$ to $\mathrm{P}$ will limit $\mathrm{P}$ uptake and lead to reductions in growth rate and bone mineralization [10]. The relationship that leads to clinical problems is not well defined, but a $\mathrm{Ca}: \mathrm{P}$ ratio greater than 1.5 should be evaluated critically. An excess of $\mathrm{Ca}$ is of little importance with the adequate concentration of $\mathrm{P}$ in the diet [10].

Pigs are more susceptible to rickets when kept confined and stunted, as rapid growth associated with lack of light can lead to disease [13]. Therefore, the only source of minerals and vitamin $\mathrm{D}$ is in the feed. In this outbreak, hypocalcemia $(-38.5 \%)$ and hypervitaminosis D $(+855.3 \%)$ were observed when 
taken into consideration the total consumed in the diet and the NRC requirements [15]. On the other hand, according to the Brazilian table for birds and pigs [17], hypocalcemia (-45.5\%) and hypovitaminosis D $(-35.3 \%)$ were observed.

Cases of rickets caused by P deficiency are not common in pigs, the most frequent cause is the lack of vitamin D leading to a deficiency in Ca absorption [7]. In addition, when raised on farms in an intensive manner, pigs are less susceptible to rickets due to dietary supplementation [7]. In this outbreak, it can be observed that the amount of Ca consumed was significantly below the necessary $[15,17]$. The Phosphorus values in the diet were slightly higher $(+12.8 \%)$ according to the Brazilian recommendation [17], but lower $(-26.6 \%)$ considering the American recommendation [15]. The amounts of vitamin D were also lower compared to the requirements [17], and far higher than the requirements [15], respectively.

According to dietary recommendations, there is a great divergence between the NRC [15] and the Brazilian Poultry and Swine Table [17], mainly referring to $\mathrm{P}$ and vitamin $\mathrm{D}$. Comparing the NRC [15] and the Brazilian table [17], Brazil recommends $13.4 \%$ more $\mathrm{Ca}, 34.5 \%$ less $\mathrm{P}$ and $985.5 \%$ more vitamin D. It is believed that these variations from the NRC [15] are related to the climatic and technological conditions considered in the Brazilian pig farming as well as to the researches carried out in Brazil.

In the literature, the most common causes for the development of rickets are hormonal deficiencies or some particular problem of animals in the absorption of minerals [14]. However, in this report, it was verified that they were not individual causes, but the amount of $\mathrm{Ca}$ in the diet.

From the analysis of the commercial product used, associated with the clinical signs and the lesions found, it was possible to conclude that the calcium de- ficiency in the diet caused the development of rickets. This disease is uncommon in an intensive pig rearing system. In the Laboratory of Pathology of the IFC, Campus Concórdia, between 2013 to 2017, 10 cases of rickets in pigs were described, in a total of 367 diagnoses (2.7\%) [5]. In Pelotas, Rio Grande do Sul, the pathology laboratory of the Federal University of Pelotas (UFPel) described that the deficiency diseases in pigs had an incidence of $2 \%$ (507 cases) between 1978 and 2015 [6]. In Santa Maria, Rio Grande do Sul, the pathology laboratory of the Federal University of Santa Maria (UFSM) described that metabolic and nutritional diseases accounted for $11.5 \%$ of the laboratorial casuistry (564 cases) from 1964 to 2011 [3].

It is concluded that rickets in pigs raised intensively occurred due to non-observance of the minimum intake levels of Ca, P and Vitamin D. Although this is an evident conclusion, when the technification of the sector in the country is taken into account, errors in the formulation of the diet leading to animal mortality and severe economic damage to farmers are not currently expected.

\section{MANUFACTURERS}

${ }^{1}$ CRQ - Produtos Quimicos Eireli. Diadema, SP, Brazil.

${ }^{2}$ Easyway Comercio e Servicos em Informática Ltda. São Bernardo do Campo, SP, Brazil.

${ }^{3}$ Control Lab Comércio de Produtos para Laboratório Ltda. São José dos Pinhais, PR, Brazil.

Acknowledgements. Work supported by grants from the Instituto Federal Catarinense (IFC) and from the National Council for Scientific and Technological Development (CNPq). Authors are grateful to Aline Rosa Consoli for the English review of the manuscript.

Declaration of interest. Authors report no conflicts of interest. The authors alone are responsible for the content and writing of the paper.

\section{REFERENCES}

1 Associação Brasileira de Proteína Animal (ABPA). 2020. Relatório Anual 2020. São Paulo: ABPA, 160p.

2 Barcellos D., Moreno A.M. \& Sobestiansky J. 2012. Deficiências Nutricionais. In: Sobestiansky J. \& Barcellos D. (Eds). Doenças dos Suínos. 2.ed. Goiânia: Cânone Editorial, pp.613-626.

3 Brum J.S., Konradt G., Bazzi T., Fighera R.A., Kommers G.D., Irigoyen L.F. \& Barros C.S.L. 2013. Características e frequência das doenças de suínos na Região Central do Rio Grande do Sul. Pesquisa Veterinária Brasileira. 33(10): 1208-1214.

4 Burtis C.A. \& Bruns D.E. 2016. Metabolismo Mineral e Distúrbios ósseos. In: Tietz Fundamentos de Química Clínica e Diagnóstico Molecular. 7.ed. Rio de Janeiro: Elsevier, pp.1578-1627. 
5 Carneiro C., Schwertz C.I., Henker L.C., Rhoden L.A., Piva M.M., Gabriel M.E., Lucca N.J., Baldi K.R.A., Casagrande R.A., Gomes T.M.A. \& Mendes R.E. 2018. Doenças Diagnosticadas pelo Laboratório de Patologia Veterinária no Quinquênio 2013-2017. Boletim de Diagnóstico do Laboratório de Patologia Veterinária. 2(1): 33-48.

6 Coelho A.C.B., Oliveira P.A., Santos B.L., Zamboni R., Silva P.E., Pereira C.M., Soares M.P., Sallis E.S.V. \& Schild A.L. 2017. Doenças de suínos diagnosticadas em criações de subsistência na região sul do Brasil. Investigação. 16(8): 56-61.

7 Craig L.E., Dittmer K.E. \& Thompson K.G. 2016. Bones and Joints. In: Maxie M.G. (Ed). Jubb, Kennedy, and Palmer's Pathology of Domestic Animals Pathology of Domestic Animals. 6th edn. St. Louis: Elsevier, pp.68-74.

8 Disnev I. 2012. Clinical and morphological investigations on the incidence of forms of rickets and their association with other pathological states in broiler chickens and their association with other pathological states in broiler chickens. Research in Veterinary Science. 92(2): 273-277.

9 Dittmer K.E., Thompson K.G. \& Blair H.T. 2009. Pathology of Inherited Rickets in Corriedale Sheep. Journal of Comparative Pathology. 141(2-3): 147-155.

10 Dritz S.S., Goodband R.D., DeRouchey J.M., Tokach M.D. \& Woodworth J.C. 2019. Nutrient Deficiencies and Excesses. In: Zimmerman J.J., Karriker L.A., Ramirez A., Schwartz K.J., Stevenson G.W. \& Zhang J. (Eds). Diseases of Swine. 11th edn. Hoboken: Wiley-Blackwell, pp.1043-1054.

11 Jacob F.G., Baracho M.S., Nääs I.A., Souza R. \& Salgado D.D. 2016. The use of infrared thermography in the identification of pododermatitis in broilers. Engenharia Agrícola. 36(2): 253-259.

12 Johnson D.W. \& Palmer L.S. 1939. Individual and breed variations in pigs on rations devoid of vitamin D. Journal of Agricultural Research. 58(12): 929-940.

13 Kahn C.M. \& Line S. 2014. Sistema Músculo Esquelético. In: Manual Merck de Veterinária. 10.ed. São Paulo: Roca, pp.1039-1058.

14 Madson D.M., Ensley S.M., Gauger P.C., Schwartz K.J., Stevenson G.W., Cooper V.L., Janke B.H., Burrough E.R., Goff J.P. \& Horst R.L. 2012. Rickets: case series and diagnostic review of hypovitaminosis D in swine. Journal of Veterinary Diagnostic Investigation. 24(6): 1137-1144.

15 National Research Council (NRC). 2012. Nutrient Requirements of Swine. 11th edn. Washington: National Academy Press, 400p.

16 Quarterman J., Dalgarno A.C., Adams A., Fell B.F. \& Boyne R. 1964. The distribution of vitamin D between the blood and the liver in the pig, and observations on the pathology of vitamin D toxicity. British Journal of Nutrition. 18(1): 65-77.

17 Rostagno H.S. 2017. Tabelas Brasileiras para Aves e Suínos: composição de alimentos e exigências nutricionais. 4.ed. Viçosa: Universidade Federal de Viçosa, 488p.

18 Welz B. \& Sperling M. 1999. The Techniques of Atomic Absorption Spectrometry. In: Welz B. \& Sperling M. (Eds). Atomic Absorption Spectrometry. 3rd edn. Weinheim: Wiley-VCH, pp.335-475. 